\title{
Cotas Raciais em Concursos Públicos e a Perspectiva do Racismo Institucional
}

Racial quotas in public contest and the perspective of institutional racism

\author{
Lucas Mateus Gonçalves Bulhões ${ }^{1}$ \\ Dyego de Oliveira Arruda ${ }^{2}$
}

\section{RESUMO}

Este artigo objetiva compreender possíveis práticas de racismo institucional que podem ocorrer na aplicação da lei 12.990/2014, que regulamentou as cotas raciais em concursos públicos. Parte-se da perspectiva de que o racismo institucional se refere à um conjunto de atitudes e práticas organizacionais que fazem, de modo intencional ou não, com que as pessoas negras sejam estigmatizadas e inferiorizadas em função do seu pertencimento racial. Em suma, foram analisados editais para cargos administrativos da Universidade Federal do Rio de Janeiro (UFRJ), de 2014 até 2018, a partir de uma abordagem metodológica qualitativa e crítica. Constatou-se que a UFRJ incorre em racismo institucional, mesmo que de modo não intencional, quando: não convoca cotistas negros no percentual definido pela legislação; pratica a segmentação de cargos, que impede com que vagas sejam destinadas para as cotas raciais; não contempla a convocação de cotistas em vagas excedentes e; permite com que as bancas de heteroidentificação sejam mais exigentes com determinados cargos. Em suma, as inferências do estudo sugerem um esforço de se (re)pensar a aplicação da lei 12.990/2014, tendo como propósito garantir a necessária reparação às pessoas negras historicamente subalternizadas no Brasil, em paralelo à possibilidade de estimular com que o serviço público seja um espaço racialmente mais inclusivo.

Palavras-chave: Ação Afirmativa; Sistema de Cotas; Racismo Institucional; Concurso Público.

\begin{abstract}
This article aims to understand possible practices of institutional racism that may occur in the application of the law 12.990/2014, which regulated racial quotas in federal public contests in Brazil. We start from the perspective that institutional racism refers to a set of attitudes and organizational practices that cause black people to be stigmatized and inferiorized, intentionally or unintentionally, due to their racial belonging. We analyzed edicts for administrative positions at the Federal University of Rio de Janeiro (UFRJ/Brazil), from 2014 to 2018, based on a qualitative and critical methodological approach. We found that the UFRJ incurs in institutional racism when, even if unintentionally: it does not call black quota holders in the percentage defined by the
\end{abstract}

\footnotetext{
${ }^{1}$ Mestrando em Relações Étnico-Raciais pelo Centro Federal de Educação Tecnológica Celso Suckow da Fonseca (CEFET/RJ). É servidor do quadro de Técnicos-Administrativos em Educação (TAEs) da Universidade Federal do Rio de Janeiro (UFRJ). Possui interesse e experiência nas seguintes temáticas de pesquisa: relações raciais; ações afirmativas; gestão da diversidade nas organizações. E-mail: lucasbulhoes@gmail.com

2 Doutor em Administração de Organizações pela Universidade de São Paulo (USP). Realizou estágio de pós-doutorado, na área de Administração, na Universidade Federal de Mato Grosso do Sul (UFMS). Atualmente, é professor do quadro permanente do Centro Federal de Educação Tecnológica Celso Suckow da Fonseca (CEFET/RJ), lecionando em cursos de graduação e no Programa de Pós-Graduação (nível mestrado acadêmico) em Relações Étnico-Raciais (PPRER) da instituição. Tem interesse e experiência nas seguintes áreas de pesquisa: políticas públicas e ações afirmativas; gestão da diversidade; desenvolvimento local/regional. E-mail: dyego.arruda@gmail.com.
} 
legislation; practices job segmentation, which prevents vacancies from being allocated to racial quotas; does not include the calling of quota holders in surplus vacancies and; allows hetero-identification newsstands to be more demanding with certain positions. In summary, the study inferences suggest an effort to (re)think about the application of law 12,990/2014, with the purpose of guaranteeing the necessary reparation to black people historically excluded in Brazil, in parallel to the possibility of stimulating the public service to be a racially more inclusive space.

Keywords: Affirmative Action; Quota System; Institutional Racism; Public Contest.

\section{Introdução}

A despeito de o Brasil ter formalmente abolido, em 1888, o regime político, jurídico e econômico que permitia com que pessoas negras fossem escravizadas no país, percebe-se que, contemporaneamente, o modus operandi da sociedade brasileira continua a se basear na hierarquização de natureza étnico-racial, expressa pelo racismo predominante principalmente nas camadas da elite econômica, política e cultural do país composta majoritariamente por pessoas brancas -, que mantêm uma certa relação de servidão para com os negros, que por sua vez compõem a maioria absoluta da população brasileira (SOUZA, 2019).

Mesmo após 130 anos da abolição formal do regime que escravizava pessoas negras, percebe-se que esse público continua a ocupar uma condição de subalternidade na estrutura social do Brasil. Segundo os últimos dados sistematizados nos anos de 2016 e 2017 pelo Instituto Brasileiro de Geografia e Estatística (IBGE), os negros representam a parcela da população com menores níveis de escolaridade (as taxas de analfabetismo beiram os $10 \%$ entre os pretos e pardos); maiores taxas de desocupação (passam dos $28 \%$ o percentual de negros desempregados, ou com ocupações precárias e informais); além de que os pretos e pardos ganham, respectivamente, $44 \%$ e $42 \%$ menos em relação às pessoas brancas, no exercício do mesmo tipo de função laboral (GOMES; MARLI, 2018; LEÃO et al, 2017).

Acrescente-se ainda a constatação de que os negros compõem a grande maioria do contingente de pessoas encarceradas no país (quase $64 \%$ do total de pessoas privadas de liberdade são negras); ao passo em que os pretos e pardos engrossam as estatísticas de assassinatos, não raro protagonizados pelo próprio aparato repressivo do Estado, que toma a população negra como o arquétipo daquilo que, em muitas circunstâncias, merece ser verdadeiramente eliminado do contexto social (DEPEN, 2019; CAMPOS; SILVA, 2018; DAVIS, 2018).

Considerando os aspectos acima sumarizados, nota-se que são urgentes as políticas de ações afirmativas que tenham como escopo amparar as pessoas negras. Em suma, as ações afirmativas representam o conjunto de estratégias, sobretudo capitaneadas pelo Estado, que almejam corrigir o quadro de exclusão e precariedade historicamente relegado aos negros no Brasil; quadro este que impede com que essas pessoas ocupem espaços de saber, de poder e de agência desde sempre monopolizados pela elite branca (MARQUES JR., 2017)

No Brasil, a legislação que primeiro reconheceu o dever do Estado em propor estratégias que objetivem a igualdade de oportunidades para o conjunto da população negra é a lei 12.288/2010, popularmente conhecida como o Estatuto da Igualdade Racial (BRASIL, 2010). Tal legislação, logo em seu artigo 1ㅇ, reconheceu que o Estado deve se envolver no conjunto de ações afirmativas, que representam medidas específicas, não raro empreendidas pelo aparato de Estado, que implicam na minimização das desigualdades provocadas pelo pertencimento racial dos indivíduos.

Na esteira do Estatuto da Igualdade Racial, a lei 12.711/2012, popularmente denominada de "lei das cotas", estabeleceu a reserva de vagas para pessoas autodeclaradas negras ou indígenas nos processos seletivos para ingresso nos cursos oferecidos pelas Instituições Federais de Ensino (BRASIL, 2012). Mais tarde, a lei 
12.990/2014 preconizou a reserva de vagas para candidatos autodeclarados negros nos concursos públicos para carreiras as mais diversas das organizações ligadas ao governo federal (BRASIL, 2014).

Parte-se da perspectiva de que as legislações acima indicadas representam arranjos jurídico-normativos que estimulam o Estado a permitir, de modo ativo, que grupos historicamente marginalizados - tais como o grupo de pessoas negras - possam ocupar espaços de saber, de poder e de agência para que, de alguma forma, haja um combate efetivo ao quadro de racismo que subjuga parcela expressiva do conjunto de pessoas negras no país.

De todo modo, uma questão que nesse momento surge é a seguinte: é possível que a operacionalização da reserva de vagas para pessoas negras, por parte das organizações públicas, resulte em alguma forma de racismo, tal como o racismo institucional, contrariando os propósitos originais das políticas de ações afirmativas?

Considera-se o racismo institucional, no escopo deste trabalho, como o conjunto das crenças e práticas, empreendidas por algum tipo de organização pública ou privada, que faz com que as pessoas negras sejam inferiorizadas e subjugadas, o que nega à essas pessoas o direito de que tenham condições plenas de existir e de desenvolver o máximo do seu potencial (CAMPOS, 2017; ALMEIDA, 2019). A recusa em contratar e/ ou promover pessoas negras no ambiente laboral; além da naturalização da ideia de que pessoas negras são mais aptas para as funções menos qualificadas e de menor prestígio social - só para citar alguns poucos exemplos - representam práticas de racismo institucional (MOREIRA, 2019).

Portanto, com base nos aspectos acima sumarizados, o presente artigo tem como objetivo compreender a possível evidência de práticas de racismo institucional na operacionalização da política de reserva de vagas para negros em concursos públicos, conforme prevê a lei 12.990/2014.

A ênfase deste artigo na discussão que envolve a reserva de vagas para negros em concursos públicos decorre da significativa preocupação dos movimentos sociais, bem como da opinião pública, em entender a dinâmica de como as cotas raciais em concursos públicos é operacionalizada.

Sabe-se que, no contexto político-econômico e cultural do Brasil, as funções públicas representam posições de significativo poder e prestígio social, numa dinâmica em que é crucial lançar luz no modo como as políticas públicas de ações afirmativas permitem com que grupos historicamente subalternizados - tais como a população negra - ocupem, de modo ativo e pleno, esses espaços.

Acredita-se que as reflexões decorrentes do presente artigo são importantes para o campo da administração pública, principalmente para que se empreendam esforços com o propósito de avaliar e, se necessário, aprimorar as políticas de ações afirmativas, que são cruciais para a reparação dos processos exclusão aos quais as pessoas negras historicamente foram submetidas, no Brasil.

\section{Racismo institucional - Algumas reflexões relevantes}

Considera-se que o racismo, de um modo geral, representa um sistema, decorrente de relações assimétricas de poder entre membros de grupos raciais distintos, que faz com que o grupo racialmente dominante empreenda uma série de estratégias, de modo intencional ou não, que implicam em desvantagens, sofrimento psíquico e até extermínio, físico ou social, de membros do grupo racialmente dominado (MUNANGA, 2001).

Dado o seu caráter sistêmico, o racismo apresenta um componente eminentemente estrutural, ou seja: está entranhado - não raro de modo indireto e, portanto, pouco evidente - nas relações entre as pessoas em um dado contexto social, numa dinâmica em que a compreensão da realidade passa pela naturalização da ideia de que é inerente à condição racial de certas pessoas a possibilidade de que elas ocupem posições 
privilegiadas na sociedade, em detrimento de um contingente de indivíduos que, pelo seu pertencimento racial, merecem ser subjugados (BONILLA-SILVA, 1997; ALMEIDA, 2019; GUIMARÃES, 2006).

Almeida (2019), ao analisar a perspectiva estrutural do racismo, considera que tal aspecto pode assumir duas outras formas de manifestação: individual e institucional. Ainda segundo o supracitado autor, o racismo individual ocorre quando uma determinada pessoa, de modo isolado e facilmente identificável, inferioriza a outra em função do pertencimento racial desta última. Não obstante, o racismo institucional representa manifestações de omissão, desprezo ou indignidade provenientes de organizações (sejam elas públicas, privadas ou do terceiro setor) para com membros de grupos raciais específicos. Deve-se ponderar, por ser oportuno, que ambas as manifestações de racismo - individual e institucional - estão imersas em um contexto cultural e, portanto, estrutural do racismo, que é endêmico em sociedades com passado escravocrata, tal como o Brasil (ALMEIDA, 2019).

Moreira (2019), ao discorrer sobre o racismo institucional, sugere que tal tipologia de racismo pode se manifestar de quatro formas: (a) quando determinados contingentes de pessoas não conseguem acessar os produtos e serviços de uma organização; (b) quando os produtos e serviços da organização são oferecidos de forma seletiva ou discriminatória; (c) quando grupos específicos de pessoas não conseguem lograr êxito nos processos seletivos para postos laborais em certas organizações e; (d) quando as chances de promoção e ascensão profissional são diminuídas em função do pertencimento racial dos indivíduos.

O racismo institucional pode ser identificado por intermédio de atitudes, processos organizacionais e/ou comportamentos, manifestados por gestores e/ou colabores de uma organização, que fazem com que pessoas sejam estigmatizadas e inferiorizadas em função de sua raça e de sua cor (HESSE, 2004). Fonseca (2015) lembra que o racismo institucional pode manifestar-se independentemente do caráter intencional da organização, ou seja: a omissão e/ou negligência da organização em criar mecanismos que efetivamente combatam qualquer tipo de tratamento diferenciado às pessoas de determinado pertencimento racial, também é uma evidência de racismo institucional.

Werneck (2016), além de Azevedo (2018), ponderam que o racismo institucional perfaz um elemento indissociável do Estado, que se apresenta de maneira indireta e intrínseca às atividades burocráticas dos órgãos públicos, assim como na aplicação das políticas públicas essenciais ao funcionamento da sociedade. Nesse ínterim, a atuação eminentemente seletiva do aparato policial do Estado, que não raro persegue, oprime e até extermina pessoas negras; além da negligência no fato de as políticas públicas, há muito tempo, se omitirem ante à necessidade de efetivamente empoderarem a população negra, representam conjuntamente - alguns exemplos de racismo institucional provenientes do aparato de Estado (OLIVEIRA, 2004).

Destaque-se que a principal consequência das práticas de racismo, de um modo geral, e de racismo institucional, em particular, é causar dor, sofrimento psíquico, além de um permanente sentimento de inferioridade que aflige pessoas do grupo racial discriminado, que sofrem com o estigma que as colocam em perene posição de subalternidade ante aos grupos raciais hegemônicos (ANDERSON, 2015; OLIVEIRA, 2004).

Portanto, dadas as especificidades acima sumarizadas, nota-se que são urgentes as estratégias de ações afirmativas, públicas ou privadas, que efetivamente combatam as manifestações de racismo, sobretudo contra pessoas negras, que notadamente compõem um grupo historicamente marginalizado e discriminado no Brasil (MUNANGA, 2001).

\section{As ações afirmativas no contexto brasileiro}

Em síntese, as ações afirmativas representam o conjunto de políticas, sejam elas de caráter público ou privado, que possuem o propósito de combater discriminações as mais diversas possíveis (de raça, gênero, 
orientação sexual, classe social etc.); bem como corrigir as consequências atuais decorrentes de práticas reiteradas de discriminação e preconceito engendradas no passado (MOEHLECKE, 2002; MUNANGA, 2001).

No Brasil, as primeiras estratégias de ações afirmativas surgiram em 2003 - antes mesmo da promulgação do Estatuto da Igualdade Racial e da lei de cotas -, no Rio de Janeiro que, por intermédio da lei estadual ํ. $4.151 / 2003$, preconizou a reserva de $20 \%$ das vagas a estudantes autodeclarados negros ou indígenas e com insuficiência financeira comprovada, nos vestibulares da Universidade do Estado do Rio de Janeiro (UERJ) e na Universidade Estadual do Norte Fluminense (UENF) (RIO DE JANEIRO, 2003). Mais tarde, a Universidade do Estado da Bahia (UNEB) e a Universidade de Brasília (UnB), valendo-se da prerrogativa legal da autonomia universitária, seguiram o mesmo exemplo do Rio de Janeiro até que, em 2012, a lei federal no 12.711 determinou a reserva de vagas para autodeclarados negros, nos certames das universidades públicas, de acordo com o percentual de negros em cada Unidade da Federação, conforme os levantamentos do perfil da população realizados pelo Instituto Brasileiro de Geografia e Estatística - IBGE (BRASIL, 2012).

Quanto aos concursos públicos, o estado do Paraná foi o primeiro do Brasil a oferecer cotas raciais também no ano de 2003, com base na lei estadual $n .-14.274$, que reservaria $10 \%$ das vagas em cargos do poder público estadual a negros autodeclarados (PARANÁ, 2003). Mais adiante, na esteira do exemplo paranaense, o Mato Grosso do Sul (em 2008), o Rio de Janeiro (em 2011) e o Rio Grande do Sul (em 2012) implementaram cotas raciais em seus concursos públicos até que, em 2014, por intermédio da lei federal no 12.990 instituiu-se a reserva de vagas para pessoas negras em concursos realizados no âmbito do governo federal.

Deve-se ponderar, por ser oportuno, que a lei 12.990/2014 preconiza, logo em seu artigo 1ํ, a reserva de $20 \%$ das vagas oferecidas nos concursos públicos conduzidos pelo governo federal para pessoas autodeclaradas negras, desde que a quantidade de vagas oferecidas no edital seja igual ou superior a 3 (três), ou seja: nos concursos com três ou mais vagas previstas em edital, aplica-se o percentual de $20 \%$ do total de vagas para se determinar o quantitativo de postos de trabalho que serão ocupados exclusivamente por pessoas negras (BRASIL, 2014).

Ante às muitas polêmicas e questionamentos que as políticas de ações afirmativas geraram, o Supremo Tribunal Federal (STF), ao ser instado a se pronunciar sobre a temática, reiterou, em mais de uma oportunidade, a constitucionalidade das estratégias de ações afirmativas. Nesse ínterim, em 2017, por intermédio da Ação Declaratória de Constitucionalidade no 41, o STF frisou o caráter constitucional da lei 12.990/2014, salientando adicionalmente que (STF, 2017): (a) é dever do Estado instituir mecanismos que evitem o cometimento de fraudes no expediente da reserva de vagas para pessoas negras em concursos públicos; (b) recomenda-se que os $20 \%$ dos postos laborais reservados às pessoas negras devem abranger as vagas decorrentes de todas as fases do concurso (e não meramente do edital de abertura) e; (c) é vedada às organizações públicas, quando da publicação do edital e "gestão" do concurso, valer-se do expediente do fracionamento das vagas de acordo com a especialização exigida, com o propósito deliberado de burlar a lei de cotas raciais nos concursos públicos e, portanto, não reservar as vagas devidas às pessoas negras.

Um aspecto que merece vir à tona é o fato de que logo nos primeiros anos de aplicação da lei 12.990/2014 bastava aos candidatos negros uma autodeclaração, atestando a sua autopercepção enquanto pessoa negra, para que fizessem jus ao direito preconizado pela supracitada legislação, que levava em conta a perspectiva do pertencimento racial manifestado pela própria pessoa. De todo modo, tal sistemática suscitou o temor de que não seriam incomuns as fraudes protagonizadas por pessoas que, mesmo sendo provenientes de outro grupo racial, atestariam - de modo fraudulento e ilegal - a sua autopercepção enquanto pessoas negras para que pudessem se beneficiar da reserva de vagas preconizada pela lei em análise (PALMA, 2019). 
Nesse ínterim, com o propósito de "equacionar" a supracitada problemática, o Ministério do Planejamento, Desenvolvimento e Gestão do Governo Federal editou, em 2016, a Instrução Normativa no 3, que criou as chamadas "bancas de heteroidentificação étnico-racial" ou "bancas de aferição fenotípica" (BRASIL, 2016). Em suma, tais bancas foram pensadas com o objetivo de avaliar tão somente as características fenotípicas (tais como cor da pele, cabelo e aparência do rosto, particularmente dos lábios e dos olhos) dos candidatos inscritos para as cotas raciais, numa dinâmica em que as bancas devem ter membros distribuídos, equilibradamente, por critérios de cor, raça, gênero e naturalidade (NUNES, 2018). Constatada eventuais tentativas de fraude, é prerrogativa das bancas de heteroidentificação excluir o candidato dos processos seletivos para os cargos públicos, salvaguardada a possibilidade de ampla defesa e contraditório (BRASIL, 2016).

Duarte e Ferreira (2017), ao analisarem detalhes da aplicação de cotas raciais em concursos públicos, salientam que mesmo com os ditames da lei 12.990/2014 há uma perspectiva de que o número de pessoas negras no serviço público ainda permaneça muito aquém, em termos proporcionais, do contingente de pessoas que se autodeclaram negras no país, principalmente porque: (a) há muitas carreiras, sobretudo as mais elitistas e com melhores níveis de remuneração, em que há o emprego de estratégias para que não sejam reservadas vagas para pessoas negras e; (b) há um contingente expressivo de funções de livre nomeação (os chamados "cargos em comissão") que não são providas respeitando-se a proporcionalidade da reserva de vagas para pessoas negras.

Mello e Resende (2019), ao discutirem a aplicação das cotas raciais nos concursos para docentes no magistério federal, concluíram que, mesmo após a vigência da lei 12.990/2014, é inferior à $5 \%$ o quantitativo de vagas que foram efetivamente ocupadas por pessoas negras por intermédio das cotas raciais, de 2014 até 2018 - período em que foram abertas mais de 15 mil vagas para docentes nas universidades federais do país.

Vitorelli (2017), por seu turno, reconhece a importância da lei que determinou as cotas raciais em concursos públicos, que representa um primeiro passo para um necessário processo de reparação às pessoas negras no Brasil. De todo modo, segundo o autor, para que a legislação perdure e se proteja das críticas mais contundentes, é crucial um processo de constante monitoramento do provimento das vagas reservadas, tendo como escopo garantir que a lei 12.990/2014 efetivamente atinja os seus potenciais beneficiários.

Portanto, as discussões acima sumarizadas indicam que, a despeito do pouco tempo de vigência da lei 12.990/2014, são profícuos os debates que sugerem a necessidade de (re)formular aspectos da legislação em tela. Espera-se que o presente trabalho, com os resultados que serão sumarizados e discutidos nos próximos tópicos, contribua com essa tão urgente e importante reflexão.

\section{Delineamentos metodológicos da pesquisa}

Para que fosse possível ter elementos para uma reflexão em torno da problemática e objetivo deste trabalho, realizou-se uma pesquisa de abordagem qualitativa e crítica. Em síntese, a perspectiva qualitativa do trabalho decorreu da necessidade de se ter maior flexibilidade para a interpretação, a partir de um viés crítico e mais "aberto", dos dados necessários para que se atendessem os objetivos definidos no trabalho.

Assim sendo, para que as reflexões do presente estudo pudessem se "materializar", optou-se por tomar um caso específico: a aplicação das cotas raciais nos concursos públicos para cargos de Técnicos Administrativos em Educação (TAEs), realizados pela Universidade Federal do Rio de Janeiro (UFRJ), no período de 2014 (ano em que passou a vigorar a lei 12.990) até 2018.

Deve-se salientar que a opção por focar as reflexões deste estudo no contexto da UFRJ decorreu da importância dessa instituição no cenário brasileiro, principalmente no que tange ao oferecimento de serviços de educação: trata-se de uma das dez melhores universidades públicas brasileiras, com mais de 47 mil 
alunos matriculados em cursos de graduação (oferecidos na modalidade presencial ou à distância), além de possuir mais de 9 mil servidores públicos de carreira, distribuídos nos mais de 70 Centros, Institutos, Faculdades, Escolas e Campi da instituição (UFRJ, 2019a e 2019b; MEC, 2017). Vale esclarecer que a carreira dos TAEs é a mais numerosa da instituição, numa dinâmica em que se partiu da perspectiva de que os concursos para tal função seriam aqueles em que, de modo mais corriqueiro, se acionaria o dispositivo da reserva de vagas para pessoas negras, conforme prevê a lei 12.990/2014.

Os dados necessários para este estudo foram provenientes dos registros públicos disponibilizados pela PróReitoria de Pessoal (PR-4), da UFRJ. Em síntese, a PR-4 divulga os editais dos concursos públicos realizados no âmbito da instituição, bem como publica as convocações dos candidatos aprovados, por cargo/área, tanto no regime de ampla concorrência quanto na reserva de vagas, a depender do caso. Nesse ínterim, destaque-se que os autores do presente artigo elaboraram um banco de dados, com o propósito de sistematizar: (I) as características dos editais publicados, no período de 2014 a 2018, para cargos de TAEs na UFRJ; (II) o número de vagas disponibilizadas no regime de ampla concorrência, e o quantitativo de vagas reservadas pelo critério racial; (III) o número de vagas efetivamente ocupadas, de acordo com as convocações realizadas ao longo do prazo de vigência do concurso, considerando os aprovados na ampla concorrência e nas cotas raciais e; (IV) a dinâmica de atuação das bancas de heteroidentificação, nomeadamente no que tange ao quantitativo de pessoas reprovadas, além dos eventuais recursos à essa instância, nos concursos em que as bancas foram efetivamente institucionalizadas.

Vale reiterar, por ser oportuno, que no supracitado banco de dados elaborado pelos autores não houve a preocupação de sistematizar detalhes da reserva de vagas para outros perfis de pessoas - portadores de deficiência, por exemplo, que são amparados pelo Decreto nํ 3.298/1999 -, uma vez que o foco deste artigo recai precipuamente nas cotas raciais destinadas às pessoas negras.

\section{As cotas raciais nos concursos para TAEs da UFRJ}

A UFRJ publicou, entre os anos de 2014 a 2018, quatro editais de concursos públicos para TAEs, com cargos distribuídos em três níveis: $\mathrm{C}$ (que exige que o candidato tenha ensino fundamental completo), D (que demanda o ensino médio) e $\mathrm{E}$ (para profissionais com ensino superior).

O primeiro concurso em que ocorreu o expediente da reserva de vagas para negros, foi o edital no. 390/2014. Ao término da vigência deste certame, em que foram convocados um total de 556 pessoas - quase cinco vezes mais em relação às vagas originalmente previstas em edital, pouco mais de um quarto das vagas ocupadas para os cargos de nível $C$ foram destinadas aos candidatos aprovados por cotas raciais; ao passo que o mesmo ocorreu para os cargos de nível D. Não obstante, apesar de os índices em tela superarem os $20 \%$ exigidos por lei, é importante destacar que não houve qualquer candidato autodeclarado negro que tenha sido convocado para os cargos de nível E.

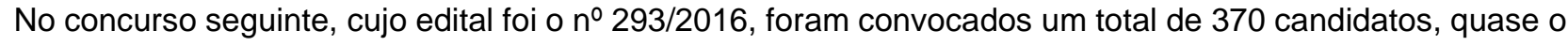
triplo das vagas que, a princípio, foram previstas no edital (UFRJ, 2016). Em suma, verificou-se que 18\% dos convocados para os cargos de nível $C$ foram cotistas, enquanto quase $9 \%$ das convocações entre as cotas foram para os cargos nível $\mathrm{D}$, e apenas $7,98 \%$ para quem tinha diploma de graduação (cargos de nível E). Como se percebe, além do fato de o preenchimento dos cargos nos três níveis não atingir o mínimo de $20 \%$ de candidatos negros convocados por intermédio das cotas raciais, observou-se também um decréscimo gradual de cotistas negros na medida que houve uma elevação no nível de exigência dos candidatos no que tange à formação acadêmica.

A mesma situação foi evidenciada na seleção subsequente, a de edital no 455/2017, na qual foram chamadas 316 pessoas para provimento nos cargos - pouco mais que o dobro das vagas originalmente previstas em edital (UFRJ, 2017a). De uma maneira geral, houve um acréscimo considerável na proporção 
de candidatos negros cotistas convocados para os cargos de nível D - na faixa dos $17 \%$-, porém observouse um declínio em relação aos de nível E, cujos convocados representaram $5 \%$, um quarto do que determina a legislação. Para os cargos de nível C, 18,7\% foram ocupados por pessoas negras inscritas para cotas ainda abaixo do mínimo legal.

Por fim, vale salientar que no último concurso realizado no período em análise, o de edital № 861/2017, foram convocados 26 candidatos $-30 \%$ a mais em relação às vagas disponibilizadas quando da publicação do edital (UFRJ, 2017b). Neste certame, porém, nenhum candidato foi beneficiado por cota racial nos cargos de níveis $\mathrm{C}$, D ou $\mathrm{E}$, uma vez que, quando da publicação do edital, não houve cargo que tenha previsto a contratação de três ou mais pessoas (expediente que, conforme prevê a lei 12.990/2014, implicaria no "acionamento" da reserva de vagas para pessoas negras).

Em resumo, durante o período de 2014 até 2018, no que tange ao provimento das vagas reservadas à cota racial, pouco menos de $17 \%$ do total - o que engloba os cargos de níveis $\mathrm{C}$, D e E - foram ocupadas por negros. Na segmentação das vagas por escolaridade, o cenário foi o seguinte: os negros cotistas representaram $25 \%$ dos convocados para os cargos de nível C, $20 \%$ daqueles que ocupariam os cargos de nível $\mathrm{D}$ e menos de $6 \%$ das pessoas nomeadas e empossadas para os cargos de nível $\mathrm{E}$, conforme ilustrado pelo gráfico 1:

Gráfico 1: Vagas ocupadas em cargos para TAEs, por escolaridade, em termos percentuais (2014 - 2018)

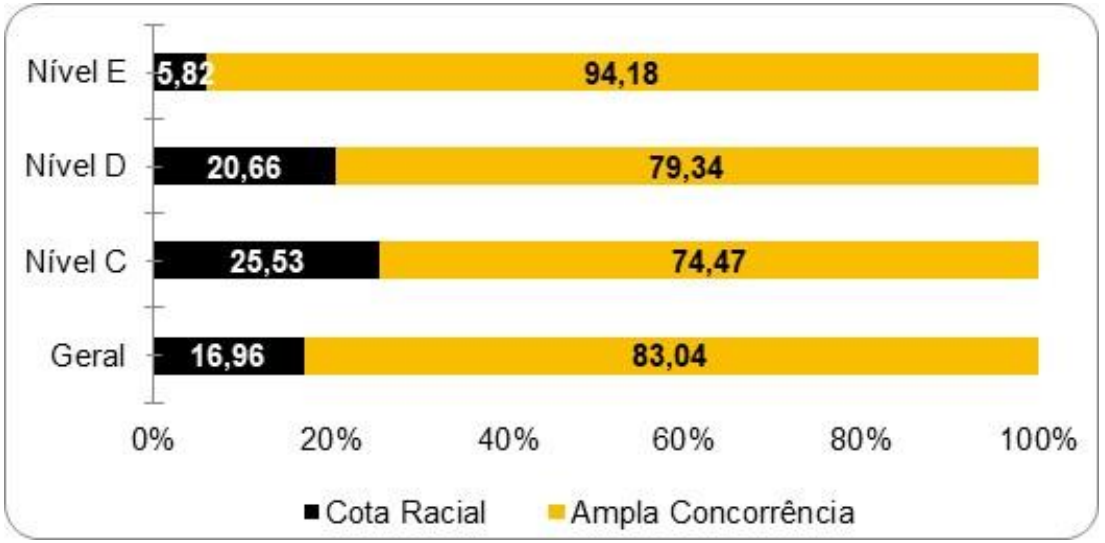

Fonte: elaborado pelos autores, 2020.

Diante da apresentação dos dados supracitados, que evidenciam dilemas na política de cotas raciais nos concursos públicos realizados na UFRJ, algumas questões se tornam prementes para se entender o que ocorreu na instituição, nos últimos anos: por que a UFRJ não atendeu de modo pleno os ditames da lei 12.990/2014, que define que o percentual mínimo de $20 \%$ das vagas por meio da política de cotas raciais a candidatos negros aprovados? E por que a legislação apenas é respeitada quando são envolvidos cargos com baixos níveis de escolarização, portanto, sem o prestígio dos postos laborais que requerem nível superior e que, consequentemente, possuem melhores remunerações?

Levando-se em consideração as perspectivas de Werneck (2016) e Azevedo (2018), que assinalam que o racismo institucional refere-se à um expediente "entranhado" na estrutura do Estado, das políticas públicas e das organizações, pode-se inferir que há fortes indícios de que a UFRJ incorra em racismo institucional quando, a partir dos dados divulgados nos parágrafos anteriores, não zela para que seja garantido, stricto sensu ao que determina a lei ํㅜ 12.990/2014, o acesso de pessoas negras às vagas que, ao menos em tese, deveriam ser reservadas para a cota racial. 
Não obstante, outro aspecto que chama a atenção refere-se ao baixo percentual de pessoas negras que foram convocadas para os cardos de nível $\mathrm{E}$ (que, notadamente, exigem formação de nível superior). $\mathrm{Na}$ medida em que a UFRJ, de alguma forma, concorre, mesmo que de modo não volitivo, para que esses cargos não sejam providos por cotistas negros, percebe-se que a instituição reforça estigmas e preconceitos que, historicamente, comprometeram a trajetória das pessoas negras no país, o que reforça a percepção de que a instituição incorre em práticas que configuram racismo institucional (FONSECA, 2015; JACCOUD, 2009).

Ao se analisar, de modo pormenorizado, a dinâmica dos editais que foram contemplados neste estudo, foi possível perceber a ocorrência de duas ações, a saber: (a) a segmentação de cargos, ou seja, a disponibilização, em edital, de várias vagas que requerem as mesmas competências e a mesma formação (em detrimento da publicização dessas vagas de modo condensado, o que "acionaria" o expediente da reserva de vagas por intermédio das cotas raciais) e; (b) a convocação de excedentes (para além, portanto, das vagas originalmente publicadas em edital), sem que sejam contemplados os candidatos aprovados para as cotas raciais, mesmo que fora das vagas, a princípio, previstas pelo edital.

No que tange à segmentação de cargos, dentre todos os postos abertos na cidade do Rio de Janeiro, no período em análise, percebeu-se que em dois quintos das vagas ocorreu, sem qualquer justificativa prévia, a separação das vagas, seja por conta do turno de trabalho ou devido ao tipo de público para o qual se destinaria o atendimento - aspectos estes que, vale dizer, são meramente administrativos (decorrentes, portanto, do "arranjo" no qual o servidor convocado irá desempenhar as suas funções), que em nada preconizam a definição de competências e habilidades específicas, quando do oferecimento da vaga em edital.

No caso do cargo de Técnico em Assuntos Educacionais - só para citarmos um exemplo mais específico as vagas foram repartidas, quando da publicação do edital $n$ ํ 455/2017, como de atendimento "geral", "ao aluno" e para a "educação especial". Como os requisitos básicos para se tomar posse nesses cargos fracionados são idênticos, subentende-se que tais medidas foram realizadas discricionariamente, ou seja: sem qualquer embasamento administrativo e/ou legal, o que pode configurar uma situação de impedimento no acesso de negros cotistas ao serviço público já que, para tais cargos, não se produzirá vagas reservadas para cota racial (por lei, com menos de três vagas previstas em edital, não é obrigatória a reserva para cotas raciais).

O quadro 1 mostra outro exemplo do fenômeno que, neste trabalho, denominados de segmentação de cargos, agora para a função de Assistente Social. É pertinente frisar que as informações do quadro constam integralmente no edital no 455/2017, um dos que foram escrutinados neste estudo.

Quadro 1: Opções de vagas para o cargo de Assistente Social (concurso UFRJ n.ำ455/2017)

\begin{tabular}{|l|l|l|l|l|l|}
\hline $\begin{array}{l}\text { Códig } \\
\text { o }\end{array}$ & Cargo & $\begin{array}{l}\text { Vagas } \\
\text { Totais }\end{array}$ & Classe & $\begin{array}{l}\text { Área de } \\
\text { atuação }\end{array}$ & Requisito \\
\hline A-104 & $\begin{array}{l}\text { Assistente } \\
\text { Social }\end{array}$ & 1 & E & $\begin{array}{l}\text { Assistência a } \\
\text { alunos }\end{array}$ & $\begin{array}{l}\text { Graduação Completa em Serviço } \\
\text { Social e registro no CRESS }\end{array}$ \\
\hline A-106 & $\begin{array}{l}\text { Assistente } \\
\text { Social }\end{array}$ & 1 & E & Hospitalar & $\begin{array}{l}\text { Graduação Completa em Serviço } \\
\text { Social e registro no CRESS }\end{array}$ \\
\hline
\end{tabular}




\begin{tabular}{|l|l|l|l|l|l|}
\hline A-107 & $\begin{array}{l}\text { Assistente } \\
\text { Social }\end{array}$ & 1 & E & Geral & $\begin{array}{l}\text { Graduação Completa em Serviço } \\
\text { Social e registro no CRESS }\end{array}$ \\
\hline
\end{tabular}

Fonte: elaborado pelos autores com base nos dados da Universidade Federal do Rio de Janeiro (2017a).

É pertinente registrar que, no último trimestre de 2019, o Ministério Público Federal (MPF, 2019), por intermédio da Procuradoria da República no Rio de Janeiro, ajuizou uma ação civil pública contra a UFRJ, sob o argumento de que a instituição desrespeita o sistema de cotas na medida em que empreende a segmentação de cargos, fazendo com que as vagas para determinadas funções não sejam publicadas, em edital, de modo aglutinado - expediente que, conforme se discutiu ao longo dos parágrafos anteriores deste artigo, implica na ausência da obrigação da reserva de vagas para pessoas negras, em consonância com o que preconiza a lei 12.990/2014. Ademais, vale dizer que a ação civil em tela revela um descumprimento às recomendações do Supremo Tribunal Federal (2017) quando do julgamento da Ação Declaratória de Constitucionalidade no 41 , que justamente indicou que as organizações públicas não podem valer-se da segmentação de cargos com o propósito de burlar a lei de cotas.

Ainda que o processo ajuizado pelo MPF não faça menção à possível prática de racismo institucional pela UFRJ, entendemos que a ação civil pública é um forte indicativo de tal aspecto, uma vez que revela uma ação, mesmo que não deliberada, por parte da UFRJ, que implica na dificuldade e/ou impossibilidade de que pessoas negras acessem postos laborais na instituição.

Em se tratando da convocação de excedentes sem que sejam contemplados candidatos negros inscritos para as cotas raciais, é notória a ausência de um dispositivo, consolidado em edital, com o qual se autorizaria a convocação futura de candidatos cotistas, caso a demanda ultrapassasse três aprovados por cargo, garantindo a presença proporcional de negros nas vagas excedentes, mesmo se estivesse publicado no documento previsão de vagas menor que o mínimo obrigatório para a determinação de cota racial (uma ou duas vagas, por exemplo). Vale frisar que o expediente aqui analisado ocorreu no concurso público para o Tribunal Regional do Trabalho do Rio de Janeiro - 1 ${ }^{a}$ Região, de número 01/2018: havia garantia expressa, em edital, da reserva de $20 \%$ das vagas, em conformidade com a lei 12.990/2014, a vigorar durante a validade do concurso, respeitando, a partir da terceira vaga excedente aberta pelo órgão, a proporção numérica estabelecida pela legislação.

A falta de garantia de convocação futura dos candidatos negros aprovados, por intermédio da cota racial, em vagas a serem criadas seria mais uma evidência da possível prática de racismo institucional pela UFRJ na realização das suas seleções públicas. Nos últimos quatro anos, $80 \%$ dos 182 cargos oferecidos na cidade do Rio de Janeiro tiveram uma ou duas vagas abertas publicadas em edital, ou seja, deixando de fora a exigência de convocação de aprovados para as cotas raciais.

Entretanto, daqueles $80 \%$ de cargos com uma ou duas vagas prévias, em mais de um terço dos casos superou-se, posteriormente, o limite de três convocados, o que nessa circunstância garantiria pelo menos uma vaga para candidato apto à cota racial. Em números, no total, 73 candidatos negros deixaram de ocupar vagas que poderiam ter sido redirecionadas para a reserva de vagas, sendo que 54 seriam inscritos em cargos de nível superior, nos quais havia maior déficit de aprovados por cota racial absorvidos para o quadro de servidores da UFRJ.

Para trazermos à baila um exemplo paradoxal das consequências da não-previsão de convocação de cotistas negros em vagas excedentes, vale citar o caso do cargo de "Médico - Clínico Medicina Interna", do concurso no 293/2016: apesar de haver apenas uma única vaga prevista em edital para o cargo em tela, constatou-se que, até o final do prazo de validade do concurso, um total de 26 pessoas foram efetivamente convocadas. Como consequência, já que o cargo sob análise, a princípio, não preconizou a reserva de 
vagas, um total de 5 pessoas negras deixaram de ingressar na UFRJ por intermédio da política de ação afirmativa, caso o expediente das cotas raciais tivesse sido aplicado nesse caso concreto.

Dos editais da UFRJ analisados neste estudo, apenas o no 455/2017 contou com a composição de uma banca de heteroidentificação étnico-racial, com o propósito precípuo de aferir tão somente os aspectos fenotípicos do candidato. Ao final do processo de verificação, pela banca, constatou-se que $47 \%$ dos candidatos que, a princípio, autodeclararam-se negros quando da inscrição no concurso, faltaram à convocação para que se apresentassem à banca.

Considerando os cargos para os quais se inscreveram os candidatos que, a princípio, autodeclaravam-se negros, as maiores faltas, em termos percentuais, foram para os cargos de nível $E$ ( $73 \%$ das pessoas que se inscreveram no concurso como negras faltaram na etapa da aferição fenotípica), seguidos dos cargos de nível C (63\% de faltantes) e nível D (37\% de faltas).

Dentre as pessoas que efetivamente passaram pela aferição fenotípica, $12 \%$ tiveram as suas candidaturas indeferidas previamente, em função de a banca julgar que esses sujeitos não possuíam os traços fenotípicos comuns entre as pessoas negras. Após a análise dos recursos (garantido o direito à ampla defesa e ao contraditório), $37 \%$ dos indeferimentos foram revertidos, numa dinâmica em que essas pessoas passaram a figurar na lista de candidatos aptos às cotas raciais.

De modo mais específico, os cargos de nível $\mathrm{E}$ foram os que apresentaram o maior índice de candidatos previamente reprovados na análise fenotípica: quase $31 \%$ - valor maior, em termos proporcionais, do que as reprovações que ocorreram nos cargos de níveis $C$ e $D$ juntas.

Chama a atenção - conforme pode-se verificar no gráfico 2 - a magnitude dos indeferimentos que foram revertidos, nos cargos de nível E, após a interposição e análise de recursos: foram pouco mais de 19\% de indeferimentos revertidos, o que, ainda assim, implicou em significativos $11,5 \%$ de pessoas que se inscreveram para esses cargos e que, mesmo após os recursos, foram consideradas não-aptas para concorrerem às vagas pelo dispositivo das cotas raciais.

Na medida em que os cargos ampliam as exigências no que tange ao nível de escolaridade dos candidatos, é perceptível o aumento no percentual de pessoas consideradas não-aptas pelas bancas de aferição fenotípica, mesmo após a interposição e análise dos eventuais recursos.

Gráfico 2: Desempenho dos candidatos autodeclarados negros na banca de heteroidentificação, em termos percentuais (edital $n^{\circ}$ 455/2017)

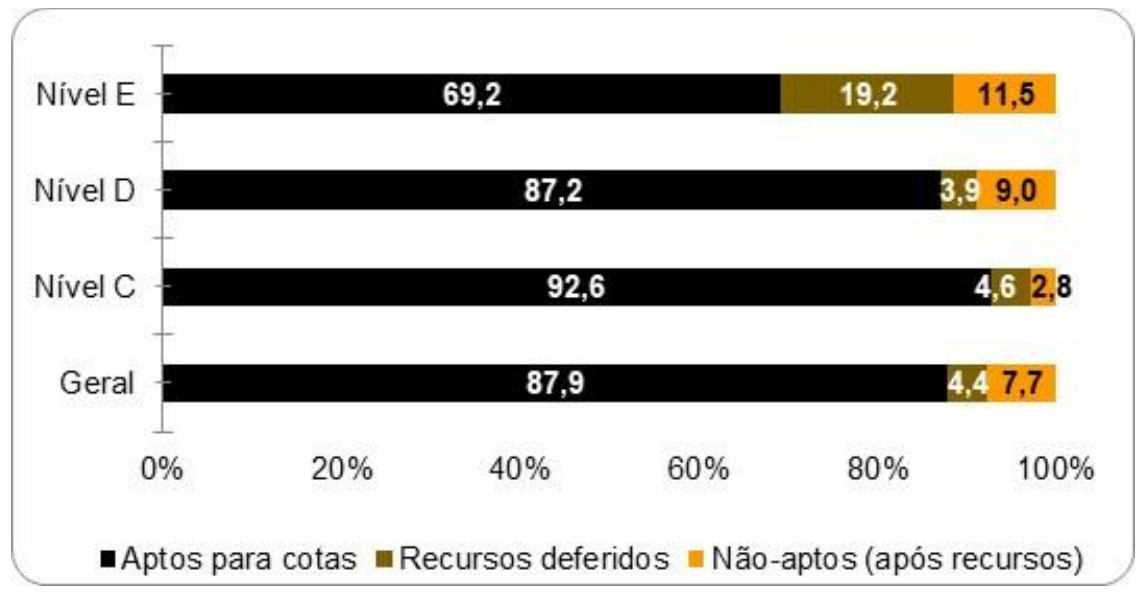

Fonte: elaborado pelos autores, 2020. 
A despeito de o aumento das reprovações pela banca poder ser explicado pela magnitude expressiva de pessoas não-negras que tentam beneficiar-se das cotas raciais para negros, devemos salientar - conforme já se discutiu neste trabalho - que é evidente que a UFRJ não empreende mecanismos efetivos para que os cotistas negros sejam convocados, de acordo com o que determina a legislação, nos cargos mais elitizados. Sendo assim, é possível dizermos, ainda que tal inferência careça de maiores comprovações em investigações futuras, que as bancas de heteroidentificação são especialmente exigentes nos cargos mais elitizados (de nível E), o que concorre para que as pessoas negras não consigam ocupar espaços que, ao menos em tese, Ihes seriam de direito, conforme determinam as políticas de ações afirmativas e, mais precisamente, a lei 12.990/2014.

\section{Considerações finais}

Dadas as informações e análises que foram empreendidas ao longo do artigo, cumpre, neste momento, rememorarmos a seguinte questão norteadora: a lei 12.990/2014, ao ser aplicada pelas organizações públicas, resulta em alguma forma de racismo, tal como o racismo institucional?

A julgar pelas informações dos concursos públicos para TAEs na UFRJ, no período de 2014 até 2018, há fortes indícios de que a instituição comete racismo institucional ao aplicar a lei 12.990/2014, principalmente por conta dos seguintes fenômenos:

- Há uma prática de se convocar candidatos negros cotistas abaixo dos $20 \%$ preconizados pela lei 12.990/2014, sobretudo para os cargos de nível E;

- Empreendem-se estratégias de segmentação de cargos, numa dinâmica em que as vagas são disponibilizadas, em edital, em um quantitativo inferior em relação ao número que obrigaria a reserva de postos laborais para pessoas negras;

- A convocação de candidatos em vagas excedentes (que surgem depois de finalizado todo o processo de seleção) ocorre sem que sejam contemplados os cotistas aprovados para as vagas reservadas por intermédio das cotas raciais e;

- Há indícios de que as bancas de heteroidentificação são mais exigentes na aferição fenotípica dos candidatos negros inscritos para os cargos de nível $\mathrm{E}$, que requerem maiores níveis de escolaridade e que possuem melhores remunerações.

Vale frisar que os aspectos acima pontuados, quando tomados em conjunto, representam ações que, em alguma medida, implicam em significativas dificuldades para que pessoas negras ocupem postos laborais na UFRJ - dificuldades essas que são "lidas", no escopo deste trabalho, como práticas que revelam racismo institucional.

Ainda que as reflexões deste estudo estejam calcadas na realidade dos concursos para TAEs da UFRJ, julgamos que os resultados aqui discutidos são relevantes indícios de que a aplicação dos ditames da lei 12.990/2014 precisa ser (re)pensada, uma vez que outras autarquias federais, de segmentos para além da área de educação, também podem incorrer nas mesmas práticas de racismo institucional protagonizadas pela UFRJ, mesmo que de modo não intencional, quando da aplicação da lei 12.990/2014.

Entendemos que o esforço de se (re)pensar a aplicação da lei 12.990/2014 poderia partir das seguintes premissas básicas:

- Garantir a convocação dos $20 \%$ de candidatos negros cotistas, stricto sensu ao que determina a legislação, para cargos de exigências e níveis os mais distintos possíveis;

- Respeitar a proporção de candidatos negros cotistas inclusive para as vagas adicionais criadas pelas instituições, mesmo que, a princípio, a quantidade de vagas previstas em edital não enseje a 
aplicação das cotas raciais. O ideal seria que tal expediente (convocação de negros cotistas em vagas excedentes) seja explicitado em edital, com o propósito de garantir que tal prática será efetivamente empreendida pelas instituições;

- Criar mecanismos de monitoramento, que inclusive envolvam o movimento negro e a sociedade civil organizada, para que sejam fiscalizados e supervisionados os editais de concursos públicos, com o propósito de se evitar o fenômeno da segmentação de cargos;

- Determinar protocolos de monitoramento da atuação das bancas de heteroidentificação, com o escopo de se evitar excessos e/ou avaliações mais rigorosas para os cargos considerados mais elitizados e que são, portanto, mais cobiçados pelos candidatos.

Mesmo que a criação e consequente aplicação da lei 12.990/2014 tenha sido um significativo passo nas estratégias para a reparação às pessoas negras historicamente subalternizadas no Brasil, ainda assim é necessário, conforme foi possível verificar neste trabalho, um conjunto de (re)formulações para que a referida lei seja, definitivamente, um mecanismo pleno e eficiente de empoderamento e reparação ao povo negro.

Por fim, sem pretender concluir e esgotar a temática explorada neste artigo, sugerimos, nos esforços de construção de uma agenda de pesquisas futuras, a investigação da condição laboral das pessoas negras que já entraram no serviço público por intermédio das cotas raciais, e a possível evidência de racismo institucional contra essas pessoas no exercício de suas funções.

\section{Referências}

ALMEIDA, Silvio Luiz. Racismo estrutural. São Paulo, SP: Pólen, 2019.

ANDERSON, Luvell. Racist humor. Philosophy Compass, v. 10, n. 8, p. 501-509, 2015.

https://doi.org/10.1111/phc3.12240

AZEVEDO, Celia Maria Marinho de. A luta contra o racismo e a questão da identidade negra no Brasil.

Contemporânea: Revista de Sociologia da UFSCar, v. 8, n. 1, p. 163-191, 2018. https://doi.org/10.4322/2316-1329.055

BONILLA-SILVA, Eduardo. Rethinking racism: toward a structural interpretation. American Sociological Review, v. 62, n. 3, p. 465-480, 1997. https://doi.org/10.2307/2657316

BRASIL. Instrução Normativa no 3, de 1 de agosto de 2016. Diário Oficial da República Federativa do Brasil, Poder Executivo, Brasília, DF, 02 ago. 2016.

BRASIL. Lei oㅜ 12.288, de 20 de julho de 2010. Institui o Estatuto da Igualdade Racial e dá outras providências. Diário Oficial da República Federativa do Brasil, Poder Executivo, Brasília, DF, 21 jul. 2010.

BRASIL. Lei no 12.711, de 29 de agosto de 2012. Dispõe sobre o ingresso nas universidades federais e nas instituições federais de ensino técnico de nível médio e dá outras providências. Diário Oficial da República Federativa do Brasil, Poder Executivo, Brasília, DF, 30 ago. 2012.

BRASIL. Lei no 12.990, de 9 de junho de 2014. Reserva aos negros $20 \%$ (vinte por cento) das vagas oferecidas nos concursos públicos para provimento de cargos efetivos e empregos públicos no âmbito da administração pública federal, das autarquias, das fundações públicas, das empresas públicas e das sociedades de economia mista controladas pela União. Diário Oficial da República Federativa do Brasil, Poder Executivo, Brasília, DF, 10 jun. 2014.

CAMPOS, Gustavo de Aguiar; SILVA, Flávia Maria Soares Pereira da. Polícia e segurança: o controle 
social brasileiro. Psicologia: Ciência e Profissão, v. 38, núm. esp. 2, p. 208-222, 2018. http://dx.doi.org/10.1590/1982-3703000213541

CAMPOS, Luiz Augusto. Racismo em três dimensões: uma abordagem realista-crítica. Revista Brasileira de Ciências Sociais, v. 32, n. 95, p. 1-19, 2017. http://dx.doi.org/10.17666/329507/2017

DAVIS, Angela. Estarão as prisões obsoletas? Rio de Janeiro: Ed. Difel, 2018.

DEPEN - Departamento Penitenciário Nacional. Levantamento Nacional de Informações

Penitenciárias - ano de 2017. Brasília: Ministério da Justiça e Segurança Pública, 2019.

DUARTE, Evandro Piza; FERREIRA, Gianmarco Loures. Sub-representação legal nas ações afirmativas: a lei de cotas nos concursos públicos. Revista de Direito Administrativo \& Constitucional, v. 17, n. 70, p. 199-235, 2017. http://dx.doi.org/10.21056/aec.v17i70.494

FONSECA, Igor Ferraz da. Inclusão política e racismo institucional: reflexões sobre o Programa de Combate ao Racismo Institucional e sobre o Conselho Nacional de Promoção da Igualdade Racial. Planejamento e Políticas Públicas - PPP, n. 45, p. 329-345, 2015.

GOMES, Irene; MARLI, Mônica. As cores da desigualdade. Retratos: a revista do IBGE, n. 11, p. 14-19, mai. 2018.

GUIMARÃES, Reinaldo da Silva. Considerações sobre um passado presente: o racismo no Brasil. 0 Social em Questão, v. 10, n. 15, p. 28-44, 2006.

HESSE, Barnor. Im/Plausible Deniability: Racism's Conceptual Double Bind. Social Identities: Journal for the Study of Race, Nation and Culture, v. 10, n. 1, p. 9-29, 2004.

https://doi.org/10.1080/1350463042000190976

JACCOUD, Luciana. (Org.). A construção de uma política de promoção da igualdade racial: uma análise dos últimos 20 anos. Brasília: IPEA, 2009.

LEÃO, Natália et al. Relatórios das desigualdades de raça, gênero e classe. Grupo de Estudos Multidisciplinares da Ação Afirmativa (GEMAA), n. 1, p. 1-21, 2017.

MARQUES JR., Joilson Santana. Políticas de ação afirmativa para negros no Brasil: elementos para uma reflexão inicial no serviço social. O Social em Questão, v. 20, n.37, p. 37-54, 2017.

MELLO, Luiz; RESENDE, Ubiratan Pereira de. Concursos públicos para docentes de universidades federais na perspectiva da lei 12.990/2014: desafios à reserva de vagas para candidatas/os negras/os.

Revista Sociedade e Estado, v. 34, n. 1, p. 161-184, 2019.

MOEHLECKE, Sabrina. Ação afirmativa: história e debates no Brasil. Cadernos de Pesquisa, n. 117, p. 197-217, 2002. http://dx.doi.org/10.1590/S0100-15742002000300011

MOREIRA, Adilson José. Racismo recreativo. São Paulo: Ed. Pólen, 2019.

MPF - Ministério Público Federal. MPF move ação contra a UFRJ por infringir sistema de cotas em concurso. 2019. Disponível em: <http://www.mpf.mp.br/ri/sala-de-imprensa/noticias-ri/mpf-move-acaocontra-a-ufri-por-infringir-sistema-de-cotas-em-concurso >. Acesso em: 07 dez. 2019.

MUNANGA, Kabengele. Políticas de ação afirmativa em benefício da população negra no Brasil: um ponto de vista em defesa de cotas. Sociedade e Cultura, v. 4, n. 2, p. 31-43, 2001.

https://doi.org/10.5216/sec.v4i2.515

NUNES, Georgina Helena Lima. Autodeclarações e comissões: responsabilidade procedimental dos/as gestores/as de ações afirmativas. In: DIAS, Gleidson Renato Martins; TAVARES JUNIOR, Paulo Roberto Faber. Heteroidentificação e cotas raciais: dúvidas, metodologias e procedimentos. Canos, RS: IFRS 
campus Canos, 2018, p. 11-31.

OLIVEIRA, Luís R. Cardoso de. Racismo, direitos e cidadania. Estudos Avançados, v. 18, n. 50, p. 8193, 2004. http://dx.doi.org/10.1590/S0103-40142004000100009

PALMA, Vanessa Cristina Lourenço Casotti Ferreira da. Educação, democracia e inclusão racial: análise da efetividade da lei de cotas para negros em concursos docentes de universidades federais. 2019. 334f. Tese (Doutorado em Educação) - Programa de Pós-Graduação em Educação, Universidade Federal da Grande Dourados, Dourados-MS, 2019.

PARANÁ. Lei Estadual no 14.274, de 24 de dezembro de 2003. Reserva vagas a afrodescendentes em concursos públicos. Diário Oficial do Estado do Paraná, Poder Executivo, Curitiba, PR, 24 dez. 2003.

RIO DE JANEIRO. Lei Estadual o 4151, de 4 de setembro de 2003. Institui nova disciplina sobre o sistema de cotas para ingresso nas universidades públicas estaduais e dá outras providências. Diário Oficial do Estado do Rio de Janeiro, Poder Executivo, Rio de Janeiro, RJ, 4 set. 2003.

SOUZA, Jessé. A elite do atraso: da escravidão à lava-jato. 1ª ed. Rio de Janeiro: Ed. Estação Brasil, 2019.

STF - Supremo Tribunal Federal. Ação Declaratória de Constitucionalidade № 41 - Distrito Federal. 2017. Diário de Justiça Eletrônico, 08 de junho de 2017. 186p.

UFRJ - Universidade Federal do Rio de Janeiro. Edital no. 293, de 10 de agosto de 2016 - Concurso Público para provimento de vagas de cargos Técnico-Administrativos. In: BRASIL. Diário Oficial da União (DOU), n. 165, 2016.

UFRJ - Universidade Federal do Rio de Janeiro. Edital no. 390, de 21 de outubro de 2014 - Concurso Público para provimento de vagas de cargos Técnico-Administrativos. In: BRASIL. Diário Oficial da União (DOU), n. 205, 2014.

UFRJ - Universidade Federal do Rio de Janeiro. Edital №. 455, de 17 de julho de 2017 - Concurso Público para provimento de vagas de cargos Técnico-Administrativos. In: BRASIL. Diário Oficial da União (DOU), n. $145,2017 a$.

UFRJ - Universidade Federal do Rio de Janeiro. Edital ํ․ 861, de 22 de dezembro de 2017 - Concurso Público para provimento de vagas de cargos Técnico-Administrativos. In: BRASIL. Diário Oficial da União (DOU), n. 247, 2017b.

UFRJ - Universidade Federal do Rio de Janeiro. Graduação em números - Dados de alunos e cursos de graduação presenciais e a distância. 2017. Disponível em: <https://xn--graduao-

2wa9a.ufri.br/index.php/grad-em-numeros $>$. Acesso em 20 nov. 2019a.

UFRJ - Universidade Federal do Rio de Janeiro. Pró-Reitoria de Pessoal (PR-4). Disponível em: $<$ http://pessoal.ufri.br/>. Acesso em 20 de nov. 2019c.

UFRJ - Universidade Federal do Rio de Janeiro. Quadro de referência dos servidores técnicoadministrativos e quadro de docentes. 2019b. Disponível em:

<https://pessoal.ufri.br/images/QRSTA MAR2019 1.pdf>. Acesso em 18 nov. 2019b.

VITORELLI, Edilson. (2017). Implementação de cotas raciais em universidades e concursos públicos: problemas procedimentais e técnicas para sua superação. Revista de Direito Administrativo, 275, 95124.

WERNECK, Jurema. Racismo institucional e saúde da população negra. Saúde e Sociedade, v. 25, n. 3, p. 535-549, 2016. http://dx.doi.org/10.1590/s0104-129020162610 